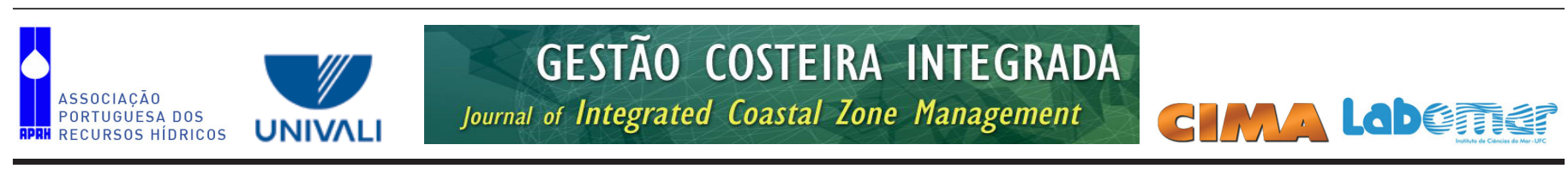

http://www.aprh.pt/rgci/pdf/rgci-358_Scherer.pdf | DOI:10.5894/rgci358

\title{
Gestão de Praias no Brasil: Subsídios para uma Reflexão *
}

\author{
Beach Management in Brazil: Topics for Consideration
}

\author{
Marinez Scherer ${ }^{1}$
}

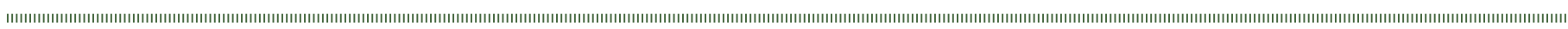

\section{RESUMO}

Este artigo apresenta a gestão de praias existente no Brasil e seus instrumentos, propondo a discussão do tema e a superação de alguns desafios. O Brasil conta com uma grande linha de costa e muitas praias. As praias são Bens de Uso Comum do Povo, sendo espaços públicos onde o direito de ir e vir deve estar sempre garantido, áreas que podem ser utilizadas por todos em igualdade de condiçóes. No entanto, percebe-se que no Brasil existe uma sobreposição de competências na gestão das praias, levando a possíveis conflitos e uma gestão ineficiente. Mesmo instrumentos desenhados para a gestáo de praias no Brasil, como é o caso do Projeto Orla - instrumento governamental, e do Programa Bandeira Azul - instrumento de iniciativa não-governamental, se demonstram de difícil aplicação devido a falta de base institucional/administrativa no Brasil, além da falta de apoio financeiro. Apresenta-se o caso da Espanha e sua Lei de Costas, como diretrizes que podem levar a uma melhor reflexão das mudanças necessárias no Brasil para que se alcance uma gestão de praias eficiente e democrática. A aceitação da necessidade de organização dos usos e atividades nas praias brasileiras é urgente. Também é urgente a aceitação de que existe sobreposição de competências, que podem gerar conflitos e que a gestão de praias deve ser compartilhada entre os múltiplos órgãos e, inclusive, usuários, aplicando-se um processo de governança.

Palavras-chave: Sobreposição de Competências, Gestão Costeira, Projeto Orla, Bandeira Azul.

\section{ABSTRACT}

This article presents beach management in Brazil and its tools. It intends to discuss the issue and possible guidelines to a better management. Brazil has a long coastline and many beaches, of many kinds too. All Brazilian beaches are public places and everyone has the right to come and go. This right should always be guaranteed, letting theses areas available for everyone on equal terms. However, it is noticed that in Brazil there is an overlap of administrations in the management of beaches, leading to possible conflicts and inefficient management, as well as private use of the public space. Many challenges are presented to beach management in Brazil such as: land ownership, tourism and urban projects control, beach bars and restaurants regulation, accessibility, biodiversity conservation, cultural aspects maintenance, erosion process control, among others. A part of that Brazilian legislation do not take in account sand dunes as part of the beaches, leading to a fragmented management of beach ecosystems. Even tools designed for beach and shoreline management in Brazil, such as Projeto Orla - a governmental project, and Blue Flag Programme - an instrument of non-governmental initiative, demonstrate to be of difficult implementation due to the lack of a solid institutional and administrative basis and lack of financial support as well. As an example it is presented the case of Spain and its Coast Act dated of 1988. As the Spanish Coast Act define beach as a public space as well, it could provide some guidelines for Brazil. It is discussed some aspects of the Spanish Coast Act and their parallel with the Brazilian norms. It is exposed the need of legislation improvement in order to achieve efficient and

1 - Universidade Federal de Santa Catarina. Centro de Filosofia e Ciências Humanas - Departamento de Geociências. Campus Universitário Trindade, Florianópolis, SC, Brasil. CEP 88.040-970.e-mail: marinez.scherer@ufsc.br 
democratic management of beaches. In general terms Brazil should guarantee free access to all beaches and introduce more efficient beach rules. It could also be good to initiate a beach classification and certification scheme, including water and sand quality. The acceptance of the need of controlling uses and activities on the Brazilian coastline is urgent and the acknowledgment that there is an overlapping of responsibilities also represents a priority, which can lead to conflicts. The management of the beaches should be shared among multiple structures and users, applying a governance process.

Keywords: Public Administration Conflict, Coastal management, Orla Project, Blue Flag.

\section{APRESENTAÇÁO}

Este artigo pretende trazer à discussão a gestão de praias existente no Brasil e seus instrumentos, propondo possíveis diretrizes, principalmente no que tange àquelas praias nas quais predomina o uso turístico e de lazer.

$\mathrm{O}$ artigo inicia-se com uma breve introdução sobre as praias e seu caráter público, para logo após discorrer sobre as sobreposiçóes legais e administrativas que incidem sobre às praias. Levanta-se também a necessidade de um maior conhecimento da dinâmica de cada praia para um planejamento de ocupaçáo ordenada e os usos e atividades desenvolvidas nas praias. $\mathrm{O}$ trabalho aponta instrumentos aplicáveis à gestão de praias no Brasil, de caráter governamental e não-governamental, assim como apresenta como exemplo o caso da Lei de Costas da Espanha. Finalizase o artigo com uma discussão sobre os temas levantados e apresentando-se algumas diretrizes para uma gestão eficiente de praias no Brasil.

\section{INTRODUÇÃO}

O Brasil conta com aproximadamente $10.800 \mathrm{~km}$ de linha de costa, sendo que as praias cobrem 82.778 hectares, correspondendo a aproximadamente $2 \%$ de todos os ecossistemas costeiros brasileiros (MMA, 2010). A beleza das praias e a presença do sol constante em algumas regiôes do país colaboram para que o Brasil se firme como destino turístico de sol e praia para a comunidade local, turistas nacionais e internacionais. Este segmento do turismo é responsável por geração de emprego, renda e riquezas, como no caso da Espanha em que o turismo balnear é responsável por $74 \%$ dos turistas estrangeiros e por mais de $10 \%$ do PIB deste país (Yepes, 1998, apud Silva \& Vaz, 2012).

$\mathrm{O}$ turismo, aliado a assentamentos urbanos, indústrias, exploração de recursos naturais, entre outras atividades, são vetores responsáveis pelo aceleramento do processo de uso, ocupação e degradação da zona costeira e das praias (Harvey \& Caton, 2003). Por outro lado, as áreas litorâneas dependem fundamentalmente de sua qualidade ambiental, e de gestão responsável, para continuar a oferecer um ambiente de qualidade e sustentável para as diversas atividades, capaz de trazer melhorias sociais, econômicas e ecológicas para a zona costeira, minimizando riscos à população (MTur, 2010).

No Brasil, as praias são Bens de Uso Comum do Povo espaços públicos onde o direito de ir e vir deve estar sempre garantido, sendo áreas que podem ser utilizadas por todos em igualdade de condiçôes (MMA, 2006). Pela legislação brasileira praia é a "área coberta e descoberta periodicamente pelas águas, acrescida da faixa subsequente de material detritico, tal como areias, cascalhos, seixos e pedregulhos, até o limite onde se inicie a vegetação natural, ou, em sua ausência, onde comece outro ecossistema", sendo um "bem comum do povo com acesso livre e franco" (Presidência da República, 1988).

Assim, praias são regiôes de uso democrático e acesso livre a todos os brasileiros, nas quais os usos e atividades devem estar regulamentados e fiscalizados. No entanto, a gestão de praias apresenta diversos desafios, como destacado pelo Projeto Orla (MMA, 2006): regularização fundiária, ordenamento dos empreendimentos turísticos e de projetos urbanísticos, ordenamento de barracas/quiosques de praia, manutenção da acessibilidade à praia, conservação de biodiversidade e de culturas tradicionais, minimização de processos erosivos; entre outros, demonstrando que nem sempre as atividades desenvolvidas nas praias são devidamente ordenadas. Além disso, as praias tem o potencial de serem um dos primeiros ambientes a sofrer as consequências das mudanças climáticas, tais como a combinaçáo da elevaçáo do nível do mar com eventos climáticos extremos mais frequentes e rigorosos.

Atualmente a boa gestão de praias e o direito de usufruir deste espaço não são sempre observados no litoral do Brasil. As iniciativas de gestão deste espaço não correspondem ao crescente uso, aos desafios eminentes das mudanças climáticas, à necessidade de acesso livre por todos, nem à necessidade de conservação da biodiversidade e da livre ação da dinâmica costeira.

\subsection{Gestão de Praias e Competências}

$\mathrm{Na}$ Carta Magna do Brasil, o Artigo 20 dita que as praias marítimas são bens da União, assim como o Mar Territorial e os Terrenos de Marinha ${ }^{1}$ e seus acrescidos (Senado Federal, 1988). Sendo assim, o que se chama de praia, para fins de ócio e lazer, são bens da união. Ainda, a Constituição Federal declara que a Zona Costeira é Patrimônio Nacional. Uma vez que a Zona Costeira no Brasil é constituída principalmente pelos municípios confrontantes ao mar e 12 milhas náuticas na parte terrestre, as praias marítimas também são Patrimônio Nacional. Não obstante, diferente de outros Bens da União, as praias também são bens de uso comum do povo, sendo, segundo o Código Civil brasileiro, inalienáveis (Presidência da República, 2002), ou seja, não podendo ser transmitidas ou vendidas.

1 - Segundo a Lei 9.760 de 1946, os Terrenos de Marinha são bens da Uniáo e são localizados na faixa de terra com 33 metros em direção a terra, contada a partir da linha da preamar média de 1831, adjacente ao mar, rios e lagoas, no continente ou em ilhas, sempre que se fizer sentir a oscilação da maré. 
Segundo as normas brasileiras, o órgão competente para a gestão dos bens da União, nos quais se inserem as praias e Terrenos de Marinha, é a Secretaria do Patrimônio da União (SPU), do Ministério do Planejamento. Uma das competências da SPU é justamente disciplinar a utilização de bens de uso comum do povo, adotando as providências necessárias à fiscalização de seu uso (SPU, 2012).

Apesar de constar como competência da SPU a gestáo e fiscalização das praias, na grande maioria das vezes tais atividades são exercidas pelo poder municipal. $\mathrm{Na}$ tabela 1 se apresenta as diferentes áreas da orla, usos predominantes (público ou privado) e, por fim, a esfera governamental de gestáo, demonstrando os conflitos e sobreposiçóes de competência nesta estreita faixa (Tabela 1). Ressalta-se que orla é definida aqui como unidade geográfica inserida na Zona Costeira delimitada pela faixa de interface entre a terra firme e o mar (MMA, 2006).

Tabela 1. Esferas governamentais com competências nas diferentes regióes das praias.

Table 1. Beach regions and public management.

\begin{tabular}{|c|c|c|}
\hline $\begin{array}{l}\text { Áreas da praia } \\
\text { (do mar para a } \\
\text { terra) }\end{array}$ & Usos predominantes & $\begin{array}{l}\text { Competência de } \\
\text { Gestão }\end{array}$ \\
\hline Mar & $\begin{array}{l}\text { Público (com } \\
\text { autorizaçóes a usos } \\
\text { privados) }\end{array}$ & Uniāo \\
\hline Praia & $\begin{array}{l}\text { Público (com } \\
\text { autorizaçóes de usos } \\
\text { esporádico a privados) }\end{array}$ & União, Prefeitura \\
\hline $\begin{array}{l}33 \text { metros / } \\
\text { Terrenos de } \\
\text { Marinha }\end{array}$ & $\begin{array}{l}\text { Público (com destinação } \\
\text { de uso público ou } \\
\text { privado sob diferentes } \\
\text { regimes: permissão } \\
\text { de uso e concessão } \\
\text { de direito real de uso } \\
\text { resolúvel, locação, } \\
\text { arrendamento, } \\
\text { alienação, ocupação, } \\
\text { cessão e aforamento) }\end{array}$ & União, Prefeitura \\
\hline Após 33 metros & $\begin{array}{l}\text { Privado (com áreas } \\
\text { públicas como praças e } \\
\text { ruas) }\end{array}$ & Prefeitura \\
\hline
\end{tabular}

Fonte: elaboração própria.

Source: Elaborated by the author

Percebe-se que no âmbito da orla aparecem duas competências administrativas mais marcantes - União $e$ Município. O governo estadual atua mais fortemente na Comissão Técnica do Projeto Orla e contratação de serviços como os guarda-vidas, em alguns estados. Destaca-se, assim, o potencial conflito de competências entre diferentes níveis de governo, o que também acaba por ser expresso nos diferentes instrumentos de planejamento e ordenamento costeiro e marinho, tais como o Plano Diretor, Zoneamento Ecológico Econômico Costeiro (ZEEC), Plano de Gestáo da Zona Costeira (PGZC), Projeto Orla (Figura 1 e Tabela 2).

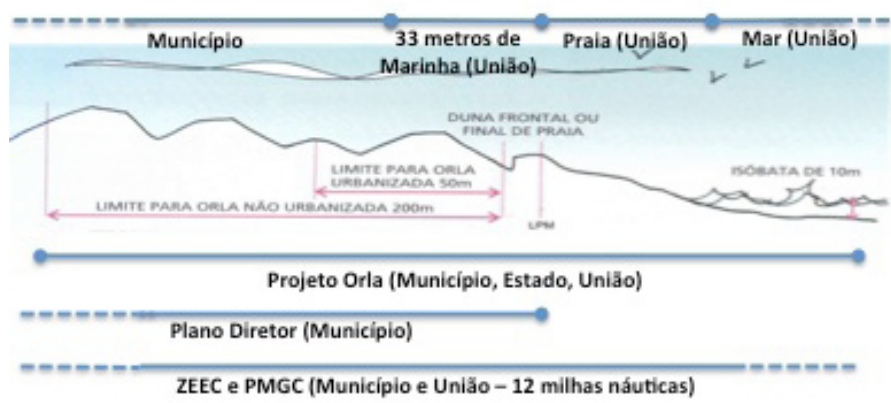

Figura 1. Perfil de orla, instrumentos e competências.

Figure 1. Coastal profile, tools and public administration.

Fonte: modificação de figura do Manual de Fundamentos para Gestão Integrada - Projeto Orla (MMA, 2006 pg.28).

Source: modified from Manual for Integrated Management Basics - Projeto Orla (MMA, 2006 pg.28).

Tabela 2. Competências de diferentes escalas da administração nos diferentes instrumentos de planejamento e gestão da orla marítima

Table 2. Administration levels and planning and management tools.

\begin{tabular}{l|c|c|c}
\hline \multirow{2}{*}{$\begin{array}{l}\text { Instrumentos de } \\
\text { planejamento e Gestáo }\end{array}$} & \multicolumn{3}{|c}{ Escalas da Administraçáo } \\
\cline { 2 - 4 } & $\begin{array}{l}\text { Governo } \\
\text { Federal }\end{array}$ & $\begin{array}{l}\text { Governo } \\
\text { Estadual }\end{array}$ & $\begin{array}{l}\text { Governo } \\
\text { Local }\end{array}$ \\
\hline Plano Diretor Municipal & & & $\mathrm{X}$ \\
\hline ZEEC/PGZC Municipal & & $\mathrm{X}$ & $\mathrm{X}$ \\
\hline Projeto Orla & $\mathrm{X}$ & $\mathrm{X}$ & $\mathrm{X}$ \\
\hline
\end{tabular}

Fonte: Elaboração própria

Source: Elaborated by the author.

$\mathrm{X}$ = quando a competência da administração pública incide diretamente sobre o instrumento.

$X=$ when the public administration focuses directly on the instrument

Instrumentos de planejamento e gestâo, definidos como tal por legislação específica, muitas vezes tem influência na mesma área. Ao analisar as Tabelas 1 e 2 e a Figura 1 percebese que existe uma sobreposição de órgãos e instrumentos de planejamento e gestão na orla, principalmente na área de praia propriamente dita (faixa de areia) e nos terrenos de marinha. Por exemplo, o Zoneamento Ecológico Econômico Costeiro (ZEEC) e o Plano de Gestáo da Zona Costeira (PGZC) do município, instrumentos do Plano Nacional de Gerenciamento Costeiro, tem incidência na mesma área que o Plano Diretor. Da mesma forma, o Projeto Orla, outro 
instrumento do gerenciamento costeiro no Brasil, tem como objetivo o planejamento participativo de áreas da união e áreas de competência do município, também já regida pelo Plano Diretor. Esta sobreposição pode levar a conflitos de competência o que, por sua vez, pode permitir o vazio administrativo.

Ressalta-se, no entanto, que o instrumento, no contexto da gestão costeira no Brasil, que tem o objetivo de planejar os usos da praia é o Projeto de Gestão Integrada da Orla Marítima - Projeto Orla.

Além da sobreposição entre os diferentes instrumentos de planejamento e gestão de orla e praia no Brasil, os mesmos nem sempre são implementados com o devido processo participativo. Todos os instrumentos de planejamento aqui apresentados pressupóem participação no seu desenvolvimento. Esta pressuposição normalmente está descrita nas normas que estabelecem estes instrumentos. No entanto, somente o Projeto Orla tem no escopo de sua metodologia, estabelecida formalmente, a maneira de como se deve dar esta participação, indo além de uma vaga recomendação. Desta maneira ao se avaliar os níveis de participação em cada instrumento, tendo como base as normas que os instituem, somente o Projeto Orla foi considerado como tendo um processo participativo de nível médio (Tabela 3). A participação em nível avançado pressuporia uma escala de maior controle cidadão (Arnstein, 1969), o que não ocorre em nenhum instrumento de gestão da zona costeira no Brasil.

Sendo a praia um lugar de usos múltiplos, é também um lugar de conflitos de interesses e usos (Williams \& Micallef, 2011). Sendo assim, a gestão deste espaço deve levar em consideração as opiniōes e necessidades dos diversos atores e segmentos representados na praia. Decisóes unilaterais e de cunho tecnicista podem náo dar resultado prático, pois a implantação das mesmas dependerá diretamente da percepção e comportamento dos usuários. Uma vez incluídos todos os usuários em processos de gestão participativa, as decisóes tendem a ser tomadas com maior conhecimento da causa e as ações necessárias poderão ser implementadas com mais propriedade.
Para que o processo participativo na tomada de decisóes seja real e eficaz, os diferentes atores devem conhecer o ambiente que está sendo ordenado e as normas existentes. Segundo Williams \& Micallef (2011), a pouca consciência e educação ambiental, assim como o desconhecimento ou desrespeito da legislação aplicável às praias, podem prejudicar a boa gestão deste ambiente. Da mesma forma, a falta de coordenação e cooperação entre os diferentes segmentos governamentais e não governamentais, leva à gestão inadequada da zona costeira, e por consequência das praias (Barragán, 2003).

\subsection{Conhecer para fazer a gestão - condição essencial}

Para que uma praia tenha uma gestão responsável, seus aspectos físicos e naturais devem ser conhecidos (Williams \& Micallef, 2011). Praias diferentes possuem diferentes dinâmicas de balanço sedimentar, propensão a processos erosivos, diferentes tipos de ondas, incidências de correntes, representando maiores ou menores riscos aos usuários, além de uma fragilidade ambiental maior ou menor (ex.: presença ou ausência de fauna e flora). Segundo Bird (1996, apud Williams \& Micallef, 2011), pelo menos 70\% das praias em todo o mundo sofrem algum tipo de processo erosivo. Então, conhecer a praia a qual se pretende ordenar, evitandose acentuar estes processos de erosão, por exemplo, é uma precaução necessária.

Contudo, nem sempre as ocupaçóes humanas e o planejamento das mesmas se atêm às condiçóes naturais das praias. Devido a natureza dinâmica das praias e sua estreita relação com os ambientes adjacentes, resulta infrutífero falar de gestão de praias sem falar de gestão da orla. No entanto, apesar de todo o conhecimento já existente de dinâmica praial e de áreas de riscos à erosão e inundação, o planejamento de ocupação das áreas adjacentes às praias parece não levar estas questóes em consideração. Assim, planeja-se cidades praianas, sem se atentar para a questão que o meio físico-natural limita as diferentes tipologias de ocupação, ou ainda, em que em certas áreas a ocupação humana não deveria ocorrer. Ariza (2012) chama a atenção para a falta de gestão integrada das praias e ecossistemas adjacentes, pois esta falta pode levar à

Tabela 3. Níveis de participação pública nos diferentes instrumentos de planejamento e ordenamento, em âmbito local, de influência nas praias.

Table 3. Public participation levels at local planning instruments affecting beaches.

\begin{tabular}{l|c|l|l}
\hline \multicolumn{4}{c}{ Níveis de Participação } \\
\hline Instrumento & $\begin{array}{l}\text { Processo participativo } \\
\text { incipiente }\end{array}$ & $\begin{array}{l}\text { Processo participativo } \\
\text { médio }\end{array}$ & $\begin{array}{l}\text { Processo participativo } \\
\text { avançado }\end{array}$ \\
\hline Plano Diretor & $\mathrm{X}$ & & \\
\hline $\begin{array}{l}\text { ZEECM/ } \\
\text { PGZC Municipal }\end{array}$ & $\mathrm{X}$ & & \\
\hline Projeto Orla & & $\mathrm{X}$ & \\
\hline
\end{tabular}

Fonte: Elaboração própria

Source: Elaborated by the author 
necessidade de desenvolvimento de obras de engenharia de proteçấo à costa, engordamento de praia, que implicam em custos não desejáveis e que são pagos pela coletividade.

Por esta razão, e na tentativa de ordenar o uso das orlas, alguns países possuem normas que regulamentam as ocupaçôes nestas áreas (ex: Lei de Costas, Jefatura del Estado/ Espanha, 1988). Nestes casos, a ocupação humana não é permitida em áreas de risco, ou, como no caso da Espanha, em áreas de Dominio Público Maritimo-Terrestre.

Assim, a discussão de uma zona de exclusão à ocupação humana, com relação a riscos costeiros, poderia não passar somente por parâmetros métricos arbitrários, por exemplo, 300 metros em ecossistema de restinga (CONAMA, 2002). A determinação de zonas de exclusão à ocupação deve ser clara e deve ser levado em consideração questôes como: que tipo de ambiente se apresenta? qual a posição da praia frente às correntes e marés? qual o risco erosivo e/ou de inundação existente? qual o risco para os assentamentos humanos?

Esta análise baseada em ambientes, ecossistemas costeiros e suas dinâmicas leva a algumas vantagens. Por um lado, estipula-seáreas mais seguras para os assentamentos humanos, de maneira a minimizar perdas humanas e materiais na zona costeira, e por outro contribui para que ambientes sensíveis e de recarga das praias não sejam artificializados, não levando a um processo de déficit sedimentar e, possivelmente, erosivo. Salienta-se também que, a partir desta análise, pode-se propor zonas de exclusão de edificações que variam, desde as mais largas até as mais estreitas. Como exemplo, poderia ser recomendando que determinados trechos da orla tenham preservados 500 metros desde a linha de praia em direção ao continente, enquanto que outras poderiam ter não mais que 50 metros, resultando em um melhor aproveitamento econômico e com maior conservação ambiental.

Neste sentido, o Estado de Pernambuco ao estabelecer sua Política Estadual para o Gerenciamento Costeiro, Artigo 10 , parágrafo $1^{\circ}$, acrescentou à definição de praia a vegetação pioneira fixadora das dunas frontais: "entende-se por praia a área coberta e descoberta periodicamente pelas águas, acrescida pela faixa subsequente de material detrítico tal como areias, cascalhos, seixos e pedregulhos, incluindo a vegetação rasteira até onde comece outro ecossistema respeitados os limites dos terrenos de marinha e dos terrenos alodiais, sujeitos a regime jurídico diferenciado" (Assembleia Legislativa de Pernambuco, 2010). As dunas são parte integrante do balanço sedimentar de uma praia e a gestão destas praias depende também da conservação das dunas. Náo obstante, muitas vezes os campos dunares são ocupados indiscriminadamente.

\subsection{Usos e Atividades nas Praias}

Apesar de diversos e usos e atividades serem desenvolvidas nas praias (pesca; prática esportiva; manifestaçóes religiosas; eventos, tais como festas de fim de ano; dentre outros), o presente trabalho teve como principal foco a análise das atividades relacionadas ao turismo, recreação e lazer, por serem estes os principais usos nas de maior afluxo de pessoas no Brasil.

O conflito de competências na gestão das praias, o pouco conhecimento do ambiente natural e a falta de participação cidadã nas tomadas de decisão levam a sérios problemas no que tange a autorizaçóes de uso da praia (ambulantes, quiosques, shows, quadras esportivas, entre outros) assim como a fiscalização e gestão desta área.

Uma visita informal a algumas praias bastante frequentadas na alta temporada leva também a verificação de que uma infinidade de usos e atividades vêm sendo desenvolvidos nesta área e que podem não possuir as autorizações necessárias. Dentre uma grande quantidade de exemplos pode-se citar alguns que se repetem, muitas vezes, ao longo de todo o litoral brasileiro: barracas e quiosques na areia da praia (ex.: Praia do Futuro, Fortaleza, CE; Praias de Florianópolis, SC); ambulantes (ex.: Praias de Florianópolis, SC); arenas esportivas (ex.: Praia de Copacabana, Rio de Janeiro, RJ); estacionamento de carros (ex.: Praias no Rio Grande do Sul); bares, mesas e cadeiras nas areias de muitas praias brasileiras. Legalmente todo e qualquer equipamento e/ou construção na faixa de praia deve estar devidamente regularizado e com as autorizaçôes pertinentes. $\mathrm{O}$ que muitas vezes não ocorre. Um dos motivos para o uso desordenado deste espaço é a sobreposição de competências na gestão do mesmo, como mencionado.

Ainda que as praias apresentem diferentes usos, na qual diversas atividades são desenvolvidas, segundo o Projeto Orla (MMA, 2006) não é admissivel a utilização privativa de áreas de uso comum do povo por expressa disposição legal, uma vez que não são bens disponiveis para esse fim, devendo a sua utilização se destinar a toda coletividade. Assim, as praias não podem ter usos privados, de maneira continuada. Alguns usos podem ser permitidos, mas somente por tempo determinado e de acordo com autorizaçóes específicas.

Segundo a Lei Federal 9636/98 (Presidência da República, 1998), que discorre sobre os Bens da Uniāo, "a utilização, a título precário, de áreas de domínio da União para a realização de eventos de curta duração, de natureza recreativa, esportiva, cultural, religiosa ou educacional, poderá ser autorizada, na forma do regulamento, sob o regime de permissão de uso." Ainda, na mesma norma, no seu Art. $6^{\circ}$ coloca-se que "a realização de aterro, construção ou obra e, bem assim, a instalação de equipamentos no mar, lagos, rios e quaisquer correntes de água, inclusive em áreas de praias, mangues e vazantes, ou em outros bens de uso comum, de domínio da União, sem a prévia autorização do Ministério da Fazenda, importará: I na remoção do aterro, da construção, obra e dos equipamentos instalados, inclusive na demolição das benfeitorias, à conta de quem as houver efetuado;....". Assim, estruturas colocadas na praia, sem autorização deveriam ser imediatamente retiradas e a área recuperada por conta de quem a ocupa.

Lembra-se também que nas praias deve ser assegurado, sempre, livre e franco acesso a elas e ao mar, em qualquer direção e sentido (Presidência da República, 1988). Segundo o Decreto 5.300 de 2004, que regulamenta a Lei 7661/88, a qual estipula o Plano Nacional de Gerenciamento Costeiro, "o Poder Público Municipal, em conjunto com o órgão ambiental, assegurará no âmbito do planejamento urbano, o acesso às praias e ao mar...". Desta maneira, fica claro o papel do município em asseguraro livre acesso à praia e ao mar, o que muitas vezes não ocorre em praias com condomínios fechados, resorts, ou mesmo urbanizaçóes que não asseguram estes acessos. 


\section{FERRAMENTAS DE GESTÁO DE PRAIAS NO BRASIL}

No Brasil existem instrumentos legais e metodológicos que poderiam conduzir a uma gestão eficaz de praias e da orla. Dentre elas, levando-se em conta que gestão é um processo político/administrativo, destaca-se duas delas, sendo uma governamental, com participação cidadã Projeto de Gestáo Integrada da Orla Marítima; e outra de base não-governamental, com participação governamental Programa Bandeira Azul. Na sequência realiza-se uma breve apresentação e consideraçóes de cada instrumento.

\subsection{O Projeto Orla}

O Projeto de Gestão Integrada da Orla Marítima (Projeto Orla) é um instrumento do Programa Nacional de Gerenciamento Costeiro, legalmente estabelecido pelo Decreto Federal 5.300 de 2004. Este projeto foi desenhado tendo como base a necessidade de ordenamento da orla terrestre e marinha, buscando a regularização fundiária e reafirmação de competências de gestão deste espaço. É um projeto de cunho patrimonial e ambiental tendo como objetivo "compatibilizar as politicas ambiental, patrimonial e urbana no trato dos espaços litorâneos, especialmente em áreas sob dominio da União, por meio de uma ampla articulação entre os três niveis de governo e a sociedade", levando-se em consideração a "função socioambiental da orla e o livre acesso a praia” (MMA, 2006).

Uma grande contribuição do Projeto Orla à gestão de praias é a sua metodologia que preconiza e pôe em prática a coordenação e cooperação entre as diversas esferas governamentais, União, Estado e Município. Além disso, a metodologia impóe mecanismosde participação, tendo manuais de auxílio à implantaçáo desta participaçáo (diagnóstico da orla e definição das açôes de gestâo de maneira participativa, por exemplo). Em verdade, é o único instrumento do Programa Nacional de Gerenciamento Costeiro que realmente determina qual o grau e como se dá a participação popular no processo de gestão.

A abrangência do Projeto Orla se estende além do ambiente praial, adentrando no mar até a profundidade de 10 metros (podendo variar dependendo do local) e na terra passando dos limites das áreas da união, praia e terrenos de marinha. O Projeto Orla adentra áreas de competência municipal, chegando a 200 metros desde a linha de costa, em áreas não urbanizadas.

Neste caso, chama-se a atenção à necessidade do Projeto Orla ser desenvolvido em conjunto com o Plano Diretor Municipal (PDM), uma vez que o PDM é o instrumento competente para determinar usos e atividades no município.

Deve-se estar atento também que o pacto entre união, município e usuários sobre os usos pretendidos na orla não deve sobrepor à legislação existente ambiental (ex.: áreas de preservaçáo permanente), ou regras de usos da praia (ex.: proibição de usos privados na faixa de areia).

Vale lembrar que a metodologia do Projeto Orla é baseada em oficinas municipais participativas, com acompanhamento da SPU, Ministério do Meio Ambiente e órgãos estaduais. Assim, o Projeto Orla traz à tona a discussão participativa dos cenários desejados para a orla trabalhada, definindo mais claramente papéis e obrigaçóes na gestão deste espaço.

Contudo, desde a criaçáo do Projeto Orla (em 2001) e sua definiçáo legal (em 2004), somente cerca de 80 municípios costeiros participaram da metodologia (dos cerca de 300 municípios com orla marítima), e menos de 60 Planos de Gestáo Integrada (PGI) foram desenvolvidos (Oliveira \& Nicolodi, 2012). Ainda, destes PGIsnão se tem informação da real implantação prática das açôes previstas. Oliveira \& Nicolodi (2012) também citam a falta de recursos humanos e de disponibilidade de recursos financeiros nosmunicípios como as principais dificuldades enfrentadas para aimplementação dos PGIs.

Segundo a coordenadora do Projeto Orla, em exposiçáo oral na reunião do GIGERCO (Grupo de Integração do Gerenciamento Costeiro) em novembro de 2011, existem vários desafios para a implementação real do projeto. Entre eles ela citou: falta de regulamentação ao acesso à praia e estruturas de praia; falta de capacitação contínua dos instrutores do projeto; e como maior desafio elencou a falta de recursos para a real implantaçáo dos Planos de Gestão Integrada da Orla, levando a não efetivação dos mesmos (GIGERCO, 2011). Salienta-se que a necessidade de absorção dos PGIs pelos Planos Diretores municipais também consiste em um entrave burocrático que muitas vezes não é ultrapassado.

Assim, percebe-se que o Projeto Orla tem uma metodologia bem concebida, incluindo participação pública no processo de diagnóstico e planejamento, mas carece de recursos financeiros e humanos, além de incentivos para o desenvolvimento em todo o litoral. Além disso, o Projeto Orla não deveria substituir o Programa de Gerenciamento Costeiro do município, uma vez que possui atuação espacialmente mais restrita e, por consequência, não analisa os diversos fatores que podem influenciar nas praias (problemas inerentes às bacias hidrográficas, por exemplo) nem todos os atores envolvidos.

\subsection{O Programa Bandeira Azul}

Aocontráriodo Projeto Orla,o ProgramaBandeiraAzul não é uma iniciativa governamental, mas uma ação desenvolvida e promovida por organizaçóes não governamentais, que preconiza a participação governamental.

O Programa Bandeira Azul existe desde 1987 no âmbito internacional e é um programa de certificação ambiental para praias marítimas, fluviais e lacustres, além de ter uma versão destinada às marinas. O Programa tem como objetivo elevar o grau de conscientização dos cidadãos em geral e dos tomadores de decisão em particular para a necessidade de se proteger o ambiente praial e costeiro, incentivando a realizaçáo de açóes que conduzam à resoluçáo dos conflitos existentes.

No processo é necessária a participação dos municípios e envolvimento de atores locais que representam os vários segmentos da sociedade civil (moradores, iniciativa privada, empreendedores, comunidades tradicionais e grupos atuantes, como ONGs e demais associaçóes) que podem colaborar na implantação e efetivação do Programa. A certificação Bandeira Azul para praias é voluntária e é sempre outorgada 
à municipalidade onde se localiza a praia que cumpriu todos os critérios. Assim, o governo municipal é o detentor da certificação, sendo o responsável pela manutenção da qualidade socioambiental da praia.

O Programa Bandeira Azul é desenvolvido internacionalmente pela FEE (Foundation for EnvironmentalEducation-FundaçãoparaEducaçãoAmbiental) que se configura em uma organização não-governamental internacional, atualmente sediada na Dinamarca. Fazem parte da FEE organizaçóes não-governamentais (ONGs) de 46 países de todos os continentes, sendo que existem 3009 praias certificadas em todo o mundo.

No Brasil o programa Bandeira Azul vem sendo implantado desde 2006 e é representado pelo Instituto Ambiental Ratones, ONG sediada em Florianópolis, SC e filiada à FEE. Atualmente existem duas praias certificadas (estados de São Paulo e Rio de Janeiro) e uma marina certificada (estado do Rio de Janeiro), sendo que mais duas marinas (no $\mathrm{RJ}$ ) e cerca de 10 praias em diversos estados estão em fase piloto de desenvolvimento das açóes para a certificação ${ }^{2}$.

Diferentemente do Projeto Orla, o Programa Bandeira Azul para praias é de caráter voluntário e não-governamental, dedicando-se somente às áreas de uso público, não analisando a ocupação de áreas privadas nem o desenvolvimento urbano diretamente. No entanto, uma urbanização desordenada poderá afetar a qualidade da água da praia, por exemplo. Assim, indiretamente o Programa Bandeira Azul analisa qual tipo de tratamento é dado aos efluentes e resíduos da comunidade que vive perto da praia em questáo.

O Programa Bandeira Azul, através do incentivo da certificação, promove melhorias na gestão das praias tais como: cumprimento da legislação de usos e atividades na faixa de areia; instalação de equipamentos de uso público como banheiros, chuveiros e rampas de acesso; imposição de acesso livre e franco e de padróes de balneabilidade excelente à praia certificada. Além disso existem outros parâmetros necessários para se cumprir todos os 32 critérios estabelecidos pelo Programa.

Com relação aos desafios de implementação de um programa como o Bandeira Azul no Brasil, salienta-se que o mesmo foi desenhado e vem sendo desenvolvido em vários países desenvolvidos (ex.: países europeus), ou em desenvolvimento (ex.: África do Sul), tendo como premissa uma base legal clara e eficaz, além de definição estável de competências.

Países de todos os continentes utilizam o Programa Bandeira Azul como umindicador da qualidade socioambiental de Praias (Petrus et al., 2012). No entanto, no Brasil o Programa tem sérias dificuldades em se desenvolver. Estando presente no Brasil desde 2006 a quantidade de praias atendidas pelo Programa Bandeira Azul é ainda pequena se comparado a países como Espanha (511 praias), Grécia (379 praias), Portugal (271 praias), ou ainda África do Sul, com 26 praias.

2 - Comunicação Pessoal de L. Bernadi, L., Coordenadora do Programa Bandeira Azul no Brasil.
Este número ainda reduzido pode ser explicado por razóes como: agentes governamentais que não se responsabilizam pela fiscalizaçáo efetiva dos usos e atividades exercidas na faixa de areia; saneamento básico ineficiente em muitos municípios costeiros; existência de conflito de competências na gestão das praias. Assim, a dificuldade de desenvolvimento de um programa deste tipo no Brasil é muito grande. Além disso, no contexto das principais dificuldades ainda podese citar a falta de apoio e de recursos financeiros para o desenvolvimento do Programa.

\section{GESTÁO DE PRAIAS NA ESPANHA - UM EXEMPLO?}

Existem diversos países com normas aplicáveis às praias e para este trabalho optou-se em apresentar o exemplo da Espanha, pois a norma espanhola tem elementos e diretrizes de usos da praia que poderiam ser pensados no contexto da gestão de praias no Brasil. Esta relação é possível, pois apesar de haver diferenças ambientais, sociais e culturais nas praias dois países, assim como existe entre praias do mesmo país, o caráter de uso público, livre e gratuito das praias espanholas encontra reflexo nas normas brasileiras.

De acordo com a Lei de Costas Espanhola (Jefatura del Estado/Espanha, 1988) as praias naquele país também são bens de domínio público. Um dos objetivos da Lei de Costas é: "Garantizar el uso público del mar, de su ribeira $y$ del resto del dominio público maritimo-terrestre, sin más execpciones que las derivadas de las razones de interés público debidamente justificadas" (Garantir o uso público do mar, da orla e de todo o domínio público marítimo-terrestre, sem exceçôes além daquelas derivadas de razôes de interesse público devidamente justificadas - tradução da autora). Esta definição confere às praias espanholas um caráter público, assim como no caso das praias brasileiras, levando a uma possível comparaçáo entre os usos e atividades permitidas nas praias dos dois países.

Importante ressaltar que esta Lei de Costas define praia em conjunto com dunas e bermas (Figura 02), o que notadamente não está na definição brasileira, conforme já mencionado anteriormente neste trabalho. Esta definição abrangente permite uma melhor gestão das praias pois proporciona uma gestão integrada entre os diferentes ambientes da orla.

Apesar de o propósito deste artigo ser analisar gestáo das praias, como espaço público, salienta-se, que na área considerada de domínio a Lei de Costas também impóe restriçōes ao uso, em até 500 desde o final das dunas, no caso de solo não urbanos (Figura 02). Nesta área define-se acessos, zona de proteção (até 200 metros), estacionamentos, equipamentos turísticos, restrições à urbanização, entre outros. Assim, além das normas ambientais que porventura existam para a proteçáo dos ecossistemas costeiros na Espanha, a Lei de Costas determina áreas de restrição ao uso independentemente do tipo de ambiente ali presente. Já no Brasil a restrição total ao uso existe somente se configurado o ecossistema de restinga (CONAMA, 2002), levando a possíveis discussóes sobre a aplicação ou não da restrição.

$\mathrm{Na}$ Lei de Costas os usos e atividades permitidas nas praias estão bem regulamentados e as competências definidas. 


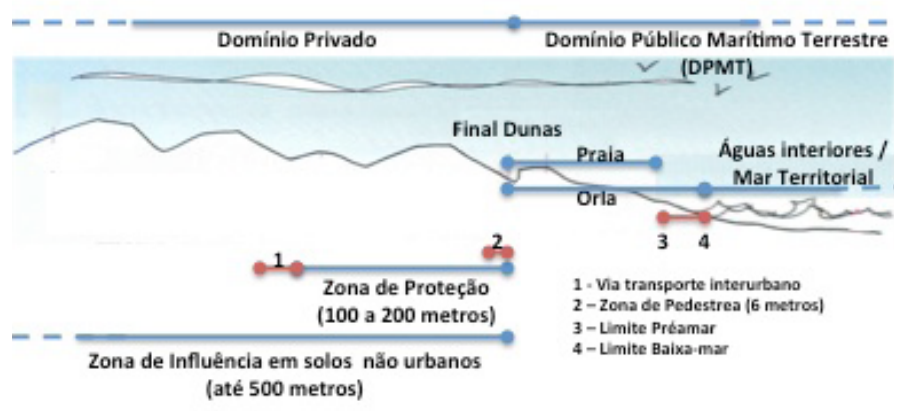

Figura 2. Perfil de orla e Lei de Costas Espanhola

Figure 2. Coastal profile and the Coast Act, Spain

Fonte: baseado da Lei de Costas Espanhola (Jefatura del Estado, 1988) e modificação de figura do Manual de Fundamentos para Gestão Integrada - Projeto Orla (MMA, 2006 pg.28).

Source: based in the Coast Act, Spain (1988), and modified from Manual for Integrated Management Basics - Projeto Orla (MMA, 2006 pg.28)

As instalações permitidas nas praias deverão ser sempre de uso público, salvo questóes definidas na lei, tal como a segurança da nação. A lei ainda determina que as instalaçóes que correspondem àquelas de prestaçáo de serviços para os usuários da praia (banheiros, chuveiros, bares,) não poderão exceder "em conjunto, a metade da superfície da praia em maré alta e se distribuirá de forma homogênea ao longo da mesma”.

Importante ressaltar que a Lei de Costas espanhola detalha, inclusive, os tipos de equipamentos que poderão ser instalados nas praias (bares, quiosques, recreação) (Figuras 03 e 04), tamanho máximo dos mesmos, distanciamento mínimo entre eles, tecnologias de saneamento aplicáveis, condição de livre acesso público, franja mínima de acesso livre na beira do mar, entre outras condiçôes. Também dá as condiçôes referentes às embarcaçóes, automóveis e publicidade na praia (Jefatura del Estado/Espanha, 1988). Já no Brasil os serviços de praia não são mencionados diretamente nas normas gerais, levando a um vazio normativo nesta questâo.

A Lei determina ainda que os municípios devem, antes do início da temporada, apresentar ao órgão competente pela gestão das praias (instituição similar à SPU no Brasil) um plano de praia. Este documento tem como objetivo favorecer a pluralidade de usos nas praias, priorizar os usos na área de domínio público marítimo terrestre, salvaguardar os valores dos bens de domínio público marítimo terrestre, conservar os espaços protegidos legalmente, garantir o acesso às praias, ordenar o uso da lâmina de água e potencializar a gestão integrada das praias (Jefatura del Estado/Espanha, 1988). O Plano de Praia deve conter todas as instalaçóes que o município considera importante para os serviços de praias, definindo como e quando será feita a seleção pública daqueles que forneceram estes serviços. São permitidas estruturas móveis na faixa de areia, mas sempre quando e se planejadas anteriormente e devidamente autorizadas pelo órgão competente. Já no Brasil, este plano de uso das praias, nos meses de maior afluxo de pessoas, não existe como instrumento legal. Neste caso, o Projeto Orla poderia vir a

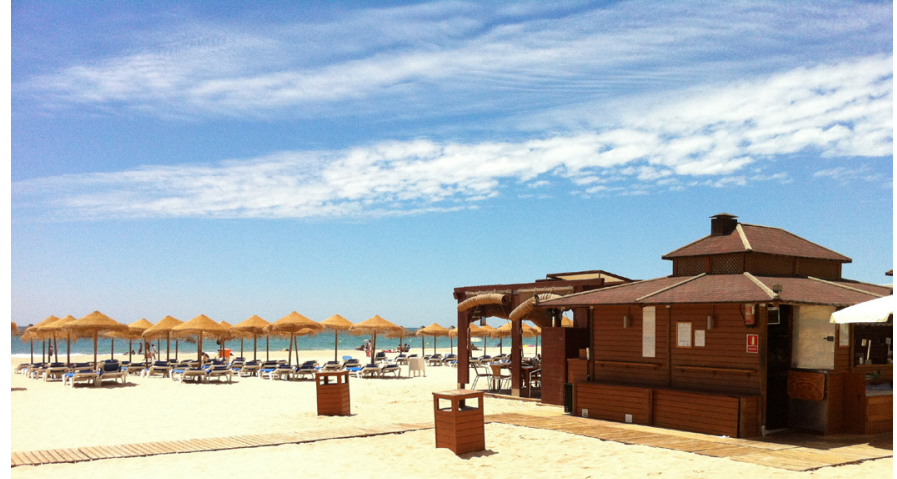

Figura 3. Bar na Praia Victoria no município de Cádiz, Espanha Figure 3. Beach bar - Victoria Beach in Cádiz, Spain

Fonte: Marinez Scherer

Source: Marinez Scherer

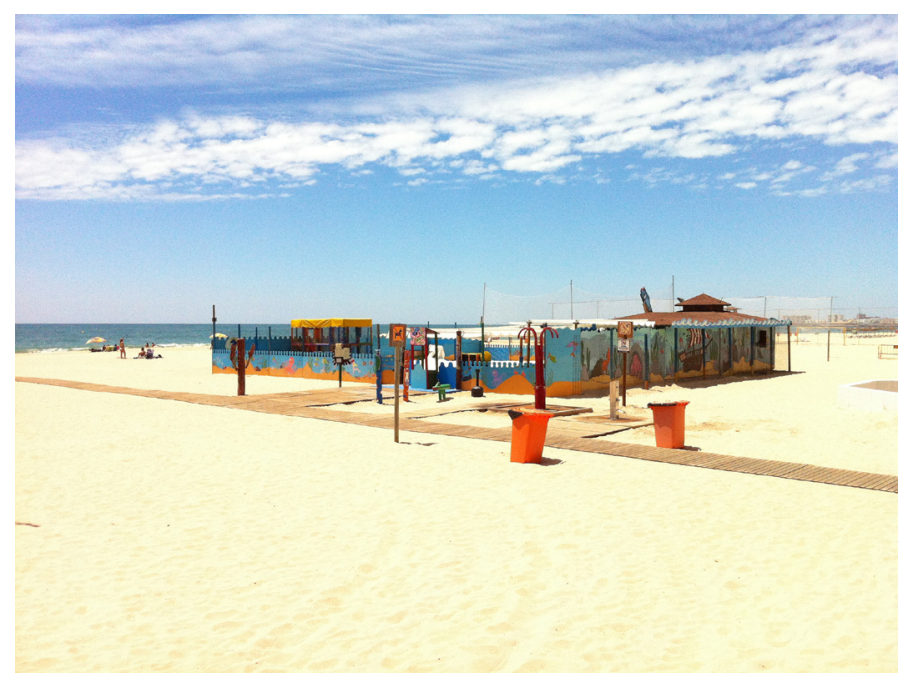

Figura 4. Área de recreação para crianças.

Figure 4. Childcare area.

Fonte: Foto por Marinez Scherer

Source: Photo by Marinez Scherer

prever tal instrumento, desde que houvesse base legal para tal.

Importante ressaltar que não é permitido nenhum tipo de publicidade nas praias. Assim, guarda-sóis e cadeiras de marcas de cervejas, por exemplo, não são vistos nas praias espanholas, diferentemente das praias brasileiras, nas quais a publicidade é largamente difundida (Figura 05).

Além disso, a gestấo das praias conta com uma comissão participativa regional, com representantes dos municípios costeiros, da sociedade civil organizada e o órgáo responsável pela gestão das praias. Esta comissão tem como funçóes o estabelecimento de critérios e diretrizes de natureza técnica relativas a: classificação e zoneamento das praias, 


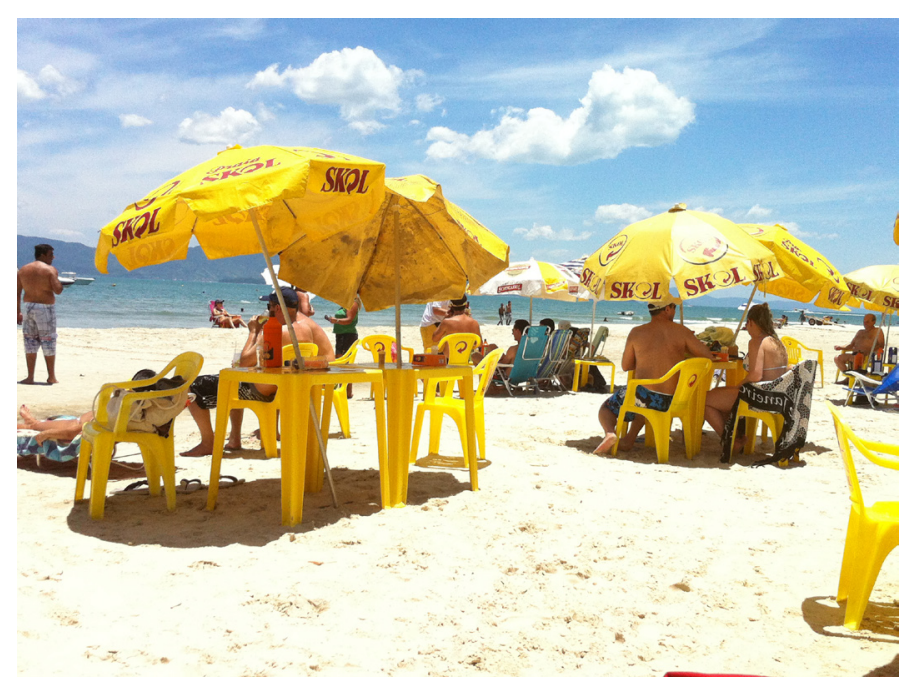

Figura 5. Mesas e guarda-sóis com propaganda em praia de Florianópolis, SC

Figure 5. Tables and chairs with publicity in Florianóplis, SC

Fonte: Foto por Marinez Scherer.

Source: Photo by Marinez Scherer.

ordenamento dos usos, exploraçáo da praia e regime de funcionamento, tempo de duração dos planos de praia, adequação dos equipamentos de praia, monitoramento e avaliação das medidas de gestâo. No Brasil, este papel poderia ser assumido pelo Comitê Gestor do Projeto Orla, uma vez que tal organização é prevista nas normas do Projeto Orla.

Atualmente a Lei de Costas espanhola está passando por uma revisão. Neste contexto, a questão das praias está sendo analisada sob a perspectiva de praias urbanas e selvagens. Possivelmente a nova Lei de Costas irá estabelecer regras de uso diferentes pare estes dois tipos de praias.

\section{CONSIDERAÇÓES FINAIS}

A gestão de praias só é possível com definição clara das competências dos diversos órgãos públicos envolvidos e deve estar baseada em conceitos e princípios de gestão integrada da zona costeira (GIZC), sendo aplicada, no entanto, na escala local (Willians \&Micallef, 2011). Assim, o planejamento das açóes que levam à gestão de praias deve ser considerado dentro do esquema metodológico da GIZC, ou seja, identificação das fragilidades e potencialidades, desenho de políticas públicas para fazer frente aos problemas e otimizar as potencialidades, determinação de uma estratégia e planejamento de implementação das açóes - Plano de Gestão, implementação do plano de gestão, análise e avaliação dos resultados, revisão do planejamento, implementação das mudanças se necessário, voltando novamente a fase de monitoramento e melhorias (Williams \& Micallef, 2011; GESAMP, 1996).

No entanto, mesmo os instrumentos governamentais desenhados exatamente para o fim de gestão da orla marítima e praias (ex. Projeto Orla), ou ainda aqueles deiniciativa da sociedade civil (ex. Programa Bandeira Azul) encontram grande dificuldade de implantação no Brasil.
Percebe-se que a lacuna entre o entendimento do problema, o planejamento e a real implantação das açóes é de grande monta. Essa lacuna reflete a tendência de outros instrumentos de gestão costeira existentes no Brasil, nos quais a fase de planejamento é diversas vezes repetida sem se chegar à implantação do que foi planejado e, muito menos, à avaliação da eficácia do mesmo. Como exemplo emblemático deste problema apontamos o Projeto Orla, pois grande parte dos Planos de Gestão Integrada da Orla Marítima desenvolvidos não são implementados de fato e a avaliação do sucesso dos mesmos é praticamente inexistente.

Apesar da falta de eficiência dos instrumentos de gestáo de praias, esta gestão é necessária e importante para muitas atividades na orla, sendo o turismo uma das atividades mais presentes. Para a estruturação de um destino turístico de sol e praia, com boa gestão das praias, há que se identificar os pontos críticos a serem vencidos. Dentre os pontos críticos pode-se destacar, de acordo com o exposto neste trabalho e de acordo com Oliveira ${ }^{3}$ e MTur (2010), os seguintes temas: a) fragilidade das articulaçóes institucionais nas três esferas de governo; b) conflitos de competência na gestão das praias com sobreposição de instrumentos de planejamento e ordenamento territorial; c) baixa participaçấo da sociedade civil nos processos de planejamento e controle social; d) não cumprimento das legislaçoóes ambientais e urbanas; e) ausência e/ou desrespeito aos instrumentos de planejamento e ordenamento territorial; $\mathrm{f}$ ) acesso às praias dificultado; $\mathrm{g}$ ) ocupação indiscriminada por atividades privadas em áreas de uso público; h) pouca capacitação dos gestores costeiros; i) falta de recursos humanos e financeiros; entre outros.

Estes fatores, além de questóes pontuais de cada praia, levam a desestruturação da praia como destino turístico de qualidade e como ambiente natural conservado. Além disso, as consequências ambientais e sociais deste mau uso dos bens públicos são importantes, com destaque para a vulnerabilidade dos ecossistemas costeiros frente à erosão e ao aumento do nível do mar.

Já os benefícios de uma gestão de praias de qualidade são enumerados por Willians \&Micallef (2011,pg. 88): utilização efetiva de um bem nacional de valor cada vez maior; aumento do turismo local e internacional; aumento na qualidade recreacional; contribuição na melhoria dos assentamentos urbanos adjacentes;aumento da proteção costeira; melhoria no monitoramento, aplicação da legislação, planejamento e tomada de decisóes;promoção do desenvolvimento costeiro sustentável.

Para tanto, algumas premissas podem auxiliar na gestáo das praias como a garantia do livre acesso às praias; a necessidade de se estabelecer mecanismos de efetividade das normas de uso das praias; a regulamentação da retirada de areia das praias; e a adoção de um sistema de classificação de qualidade ambiental de praias considerando indicador de saúde pública e qualidade ambiental, incluindo qualidade de água e areia (Agência Costeira, 2010).

3 - Comunicação oral de M. R. L de Oliveira na mesa de debates "Turismo Náutico e de Sol e Praia no Brasil: práticas e desafios” no Salão do Turismo 2009, São Paulo, Brasil. 
A aceitação da necessidade de organização dos usos e atividades nas praias brasileiras é urgente. Também é urgente a aceitação de que existe sobreposição de competências, que podem gerar conflitos e que a gestão de praias deve ser compartilhada entre os múltiplos órgãos e, inclusive, usuários, aplicando-se um processo de governança.

O Brasil necessita de uma revisão realista e competente dos usos permitidos pelas regras existentes, assim como dos instrumentos de gestão de praias, e sua real aplicação. Ao analisar o caso espanhol percebe-se que a Espanha admite serviços de praia e, ao admitir estes serviços, abre-se a possibilidade de regulamenta-los. Já no Brasil, a regra do "nada pode, tudo se faz" parece prevalecer.

A gestão das praias marítimas para um país como o Brasil, com uma grande costa litorânea é muito importante. Um país que pretende sediar dois eventos internacionais vinculados ao esporte (Copa do Mundo de Futebol em 2014 e Jogos Olímpicos em 2016), divulgando o país e suas belezas naturais no âmbito internacional, não deveria apresentar conflitos de competências de gestão, em específico nas praias. $\mathrm{O}$ Brasil poderia aproveitar a oportunidade de convergência de recursos, vontade política e incentivo internacional e nacional para implementar uma gestáo das praias eficiente e participativa. Desta maneira o país poderá apresentar como opção de lazer à comunidade local, aos visitantes internacionais e nacionais, praias com capacidade de atendimento ao público, com infraestrutura e serviços, sem problemas de balneabilidade e que respeitem a cultura e história local, deixando um legado a toda a naçáo brasileira.

\section{AGRADECIMENTOS}

Agradeço à Agência Brasileira de Gerenciamento Costeira, aos Técnicos do Projeto Orla da Secretaria do Patrimônio da União e do Ministério do Meio Ambiente, à equipe Coordenadora do Programa Bandeira Azul no Brasil, à Demarcación de Costas en Andalucía-Atlántico (Cádiz, Espanha), aos revisores deste artigo e a todas as pessoas e instituiçóes que contribuíram para as experiências e aprendizado em gestão de praias.

\section{BIBLIOGRAFIA}

Agência Costeira (2010) - Relatório de propostas para Gestão de Praias advindo do Ciclo de Debates Cidades Costeiras Sustentáveis. Agência Brasileira de Gerenciamento Costeiro, Brasília, DF, Brasil. Não Publicado.

Ariza, E. (2012) - Análisis de la Calidad de las Playas e de las Instituciones que las Gestionan: recomendaciones basadas en los estudios de las costas Catalana, en España, y del estado de Florida, en Estados Unidos. Anais do I Congreso Iberoamericano de Gestión Integrada de Áreas Litorales. 408-417. ISBN: 978-8469518236.

Arnstein, Sherry R. (1969). A Ladder of Citizen Participation. AIP Journal, 35(4):216-224. http://www.planning.org/ pas $/ \mathrm{memo} / 2007 / \mathrm{mar} / \mathrm{pdf} / \mathrm{JAPA} 35 \mathrm{No} 4 . \mathrm{pdf}$

Assembleia Legislativa de Pernambuco (2010) - Lei14.258, de 23 de Dezembro de 2010. Institui a Política Estadual de Gerenciamento Costeiro, e dá outras providências. Disponível em http://www.cprh.pe.gov.br/ARQUIVOS_ ANEXO/Lei Est 14258;141010;20101228.pdf
Barragán, J.M.M. (2003) - Medio Ambiente y Desarrollo en Areas Litorales: introducción a la planificación y gestión integradas. 306p., Universidad de Cádiz, Servicio de Publicaciones, Cadiz, Espanha. ISBN 8477868298.

CONAMA (2002) - Resolução CONAMA ño. 303, de 20 de março de 2002. Dispóe sobre parâmetros, definiçôes e limites de Areas de Preservação Permanente. Conselho Nacional de Meio Ambiente do Brasil (CONAMA), Diário Oficial da União de 13 de maio de 2002, Seção 1, página 68. Disponível em http://www.mma.gov.br/port/conama/ res/res03/res34103.xml

GESAMP (1996). The Contributions of Science to Coastal Zone Management. 67p., Joint Group of Experts on the Scientific Aspects of Marine Environmental Protection (GESAMP), GESAMP Reports and Studies No. 61, IMO/FAO/UNESCO-IOC/WMO/WHO/IAEA/UN/ UNEP, Roma, Italia. Disponível em ftp://ftp.fao.org/ docrep/fao/003/w1639e/w1639e00.pdf

GIGERCO (2011) - Ata da $41^{\circ}$ Reunião do GIGERCO. Grupo de Integraçấo do Gerenciamento Costeiro (GIGERCO), Brasília, DF, Brasil. Disponível em http://www.mma.gov.br/estruturas/sqa_sigercom/_arquivos/ ata_41_sesso_do_gi_gerco_rev27_janeiro_2012_78.pdf

Harvey, N.; Caton, B. (2003) - Coastal Management in Australia. 342 p., Oxford University Press, Melbourne, Australia. ISBN: 0195537947

Jefatura del Estado/Espanha (1988). Ley 22/88 de Costas. http://mediterranea.org/cae/ley_de_costas.htm

MMA (2010) - Panorama da Conservação dos Ecossistemas Costeiros e Marinhos no Brasil. 148p., Ministério do Meio Ambiente (MMA), Secretaria de Biodiversidade e Florestas/Gerência de Biodiversidade Aquática e Recursos Pesqueiros, Brasília DF, Brasil. ISBN: 9788577381425. http://www.mma.gov.br/estruturas/205/_ publicacao/205_publicacao03022011100749.pdf

MMA (2006) - Projeto Orla: fundamentos para a gestão integrada. 74p., Ministério do Meio Ambiente (MMA) / MinistériodoPlanejamento, OrçamentoeGestão, Braslília, DF, Brasil. ISBN: 8577380297. http://www.mma.gov. br/estruturas/orla/_arquivos/11_04122008111238.pdf

MTur (2010) - Sol e Praia: orientaçóes básicas. 57p., 2a Ed., Ministério do Turismo (MTur), Secretaria Nacional de Políticas de Turismo, Departamento de Estruturação, Articulação e Ordenamento Turístico, CoordenaçãoGeral de Segmentação, Brasília, DF, Brasil.

Oliveira, M.R.L; Nicolodi, J.L. (2012) - A Gestão Costeira no Brasil e os dez anos do Projeto Orla. Uma análise sob a ótica do poder público. Revista da Gestão Costeira Integrada, 12(1):89-98. DOI:10.5894/rgci308

Petrus, J.M.; Grimalt, M.; Sanz, A.; Genovart, M.C. (2012) - Análisis y Clasificación de Playas de Mallorca en Función de su Intensidad de Uso y Características Territoriales. Anais do I Congreso Iberoamericano de Gestión Integrada de Áreas Litorales, pp.451-459. ISBN: 13: 978-8469518236

Presidência da República, Casa Civil (2002) - Código civil. Publicada no Diário Oficial da União de 11 de Janeiro de 2002. Disponível em: http://www.planalto.gov.br/ ccivil_03/Leis/2002/110406.htm. 
Presidência da República, Casa Civil (1998) - Lei no 9.636, de 15 de maio de 1998. Dispóe sobre a regularização, administração, aforamento e alienação de bens imóveis de dominio da União. Diário Oficial da União de 18 de Maio de 1998, Brasília, DF, Brasil. Disponível em: http://www. planalto.gov.br/ccivil_03/Leis/L9636.htm.

Presidência da República, Casa Civil (1988) - Lei no . 7.661/88 Institui o Plano Nacional de Gerenciamento Costeiro. Publicada no Diário Oficial da União de 18 de Maio de 1998, Brasília, DF, Brasil. Disponível em: http://www.planalto.gov.br/ccivil_03/leis/L7661.htm.

Senado Federal (1988) - Constituição da República Federativa do Brasil. Senado Federal, Brasília, DF, Brasil. Disponível em:http://www.senado.gov.br/legislacao/const/con1988/ CON1988_05.10.1988/CON1988.pdf

Silva, C.P. da; Vaz, B. da (2012). A Definiçẫo da Capacidade de Carga de Praias como Instrumento para a Gestão e Ordenamento de Áreas Turísticas Litorais: O caso de Portugal. Anais do I Congreso Iberoamericano de Gestión Integrada de Áreas Litorales, pp. 398-406. ISBN: 9788469518236.
SPU - Secretaria do Patrimônio da União / Ministério do Planejamento, Orçamento e Gestão, Brasil (2012) - Secretaria do Patrimônio da União - SPU. Competências. Portal eletrônico do Ministério do Planejamento, Orçamento e Gestáo. Disponível em http://www.planejamento.gov.br/link_secretaria. asp? $\operatorname{cod}=8266 \& \mathrm{cat}=698 \mathrm{sec}=98 \mathrm{sub}=$

Williams, A.T; Micallef, A.(2011). Beach Management: principles and practice. 480p., Earthscan Ltda, London, U.K. ISBN: 978-1849713078. 